\title{
Moving academic research forward during COVID-19
}

\author{
$B y$ N. S. Wigginton ${ }^{1,2}$, R. M. Cunningham ${ }^{1}$, R. H. Katz $^{3}$, M. E. Lidstrom ${ }^{4}$, K. A. Moler ${ }^{2}$, D. Wirtz ${ }^{5}$ M. T. Zuber ${ }^{6}$ \\ ${ }^{1}$ University of Michigan, Ann Arbor, MI, USA. ${ }^{2}$ Stanford University, Stanford, CA, USA. ${ }^{3}$ University of California, Berkeley, CA, USA. ${ }^{4}$ University of Washington, Seattle, WA, \\ USA. ${ }^{5}$ Johns Hopkins University, Baltimore, MD, USA. ${ }^{6}$ Massachusetts Institute of Technology, Cambridge, MA, USA. Email: nwigg@umich.edu
}

A gradual, stepwise approach to reopening, informed by public health expertise, will be essential

The coronavirus disease 2019 (COVID-19) pandemic has led to an unprecedented disruption of society. Institutions of higher education have been no exception. To preserve the safety of their communities and adhere to public health guidance, universities and colleges around the world have rapidly pivoted to fully online teaching and learning models, implemented remote work for the majority of employees, and shuttered countless public spaces and programs. Most "on-site" research activities-in laboratories, in clinics, or in the fieldalso ground to a halt. Many institutions are now planning or implementing a ramp-up of on-site research activities, which offers an opportunity to begin implementing policies and practices that will lay the groundwork for the eventual reopening of additional on-site academic programming, including teaching. To ramp up safely, institutions are working with stakeholder groups-such as public health experts, as well as faculty, staff, and students-to develop guiding principles that will help inform and drive decision-making over the coming months. We synthesized several risk and decisionmaking frameworks under development at our universities to develop a set of criteria informed by public health expertise that institutions should consider before and during the first stages of restoring research activities and less certain factors to consider for subsequent phases.

Ramping down academic research and development around the world will undoubtedly contribute to the longterm economic ramifications of COVID-19. In addition to supporting the teaching and service missions of higher education-and health care delivery within academic medical centers-academic research contributes greatly to global economic development. In the United States, for example, higher education institutions accounted for $\$ 74$ billion, or $\sim 13 \%$, of the $\$ 580$ billion spent nationally on research and development in 2018 (1). More critically, these same institutions accounted for nearly half of the $\$ 96$ billion spent on basic research nationwide, often seen as the seed corn for innovation and industry. Moreover, academic research institutions are among the top five employers in 44 of 50 U.S. states, employing more than 560,000 people (and more than 300,000 trainees) directly on research funds (2), many of which cannot perform their work remotely.

\section{RAMPING DOWN}

Public health mitigation strategies across the globe have affected on-site research to varying degrees. In China, university research was subject to strict control measures in Wuhan and elsewhere, which contributed to the mitigation of the spread of the virus across the country (3). In Australia, where COVID-19 remains under greater control owing to early mitigation efforts, universities moved classes online, but social distancing measures and encouraging nonessential work from home when possible were deemed sufficient to keep most research facilities at least partially open.

In countries and regions where community transmission has been most severe-including the United States, Europe, and China-most academic institutions implemented policies to cease all "nonessential" on-site research activities over a short time frame, in some cases just a few days. This included not only laboratory research in the physical and life sciences but also field-based activities involving travel or direct human contact, such as clinic-based health, social, or educational research. Exemptions for accessing facilities on campus were solely made for work required to maintain equipment, preserve specialized research materials or longterm experiments, perform research to address the ongoing pandemic or other research deemed essential, or ensure patient, animal, and laboratory safety. Although varying widely by discipline and region, we estimate that these restrictions have halted more than $80 \%$ of on-site research activity at our six institutions.

\section{RAPID RESPONSE}

Despite the myriad challenges associated with ramping down on-site activities, research institutions worked closely with state and federal governments, funders, private industry, and each other to maintain continuity of research operations. In the United States, universities and their associations have been working closely with federal agencies to clarify what activities are allowed under active grants (e.g., salary continuity for researchers who aren't able to work on-site). Other coordination efforts include commitments to open sharing of data and research findings during the pandemic (4), improving access to high-performance computing resources for COVID 
research (5), and licensing terms that prioritize access to potentially life-saving technologies (6).

Academic researchers have also greatly contributed to work that directly addresses the ongoing pandemic-from revealing the fundamental biology of severe acute respiratory syndrome-coronavirus 2 (SARS-CoV-2), to studying the vast social, behavioral, and economic impacts felt across world, to developing the tests, therapies, and vaccines that will help treat the disease and prevent its transmission. Researchers around the globe have published more than 13,700 papers on SARS-CoV-2 or COVID-19 (7) and posted more than 3700 preprints to the bioRxiv and medRxiv repositories as of 19 May 2020.

Institutions are also assisting with critical public health services such as testing and providing the public and decision-makers with real-time data about the pandemic. For example, Johns Hopkins University's international COVID-19 dashboard receives 1.5 billion views each day, providing invaluable data on total confirmed cases, deaths, recovery rates, bed occupancy, intensive care unit availability, and more (8). Overall, the collaborations and open sharing of data and knowledge across international borders have proven to be essential in the response to the pandemic and to the reopening of other economic sectors.

\section{GUIDANCE FOR PHASED RAMP-UP}

Months after most on-site research was shut down, institutions in China, Europe, and the United States have slowly started resuming on-site research. Institutions have developed principles and policies for resuming on-site research activities based on input from public health and biosecurity experts, faculty, staff, students, and other community members. Our six universities, which represent a range of public and private institutions under varying state and local mandates and levels of local virus transmission, have developed overlapping yet distinct guidance for our research communities (see https://doi.org/10.3886/E119503V1). Common themes within our plans and elsewhere center around the critical need to adhere to public health guidance, prioritize the health and safety of the workforce and participants, and implement fair and transparent processes for decision-making. However, our plans, as well as others around the United States and in other countries, also diverge in ways that may be determined by a host of other factors, from cultural norms on campuses to local and state regulations. Policies such as allowing on-site undergraduate researchers, deciding acceptable occupancy levels in facilities, deciding whether to prioritize certain buildings and activities at the expense of minimal access to everyone, permitting use of nonlaboratory on-site spaces-including libraries, offices, and studios-and allowing field research that does not involve human subjects are among the primary differences in institutional responses.
Variations in ramp-down and ramp-up approaches often reflected differing local and state guidelines or mandates, where political and social pressures have the potential to conflict with the best public health recommendations.

Public health frameworks provide a critical and helpful risk-based assessment for when certain industries, governments, and the economy more broadly can reopen [e.g., (9)]. Academic institutions represent a broad set of activities and associated risk where one size (and one policy) does not fit all; however, it is clear from public health expertise that a gradual, stepwise approach to reopening and operating will be essential [see the table; (10)]. Furthermore, the use of metrics both in the community and within institutions will help determine if and when it is suitable to move into the next phase. On-site testing, contact tracing, and determining immunity status will likely play important roles not just in institutional decision-making and risk mitigation but also for broader public health monitoring (11). To do so, institutions will also have to consider how these strategies for research complement strategies being discussed for their broader campus community, as well as weigh potential costs, resources, and privacy concerns. Other metrics that will help determine when institutions are prepared to move into the next phase include building and laboratory occupancy rates, rates of adherence to physical distancing guidelines, and the number of new cases and symptomatic individuals identified during screening (see the box).

Future ramp-up and stabilization phases should be cautious and flexible enough that research activity can also ramp back down if metrics, public health guidance, or other external factors (e.g., local health care system capacity) dictates. Within institutions, this may also be required for certain laboratories, floors, or buildings if cases are identified and researchers are required to self-quarantine after possibly being exposed to a sick co-worker.

Further control measures will be required for months or more, such as continued physical distancing, engineering controls, requiring personal protective equipment, and administrative controls that include staggering access to spaces through shifts to minimize interactions between personnel (9). Although our suggestions are intended to prioritize caution and reversibility, we are concerned that other ramp-up plans might instead reopen too quickly or without proper safeguards out of a desire to return to prepandemic operations as soon as possible. As we are seeing in countries or other sectors that are prematurely reopening, undesired outcomes such as new transmission and outbreaks could lead to a whiplash effect of being fully open and then back to fully closed. Gradually and carefully resuming on-site research, and demonstrating that mitigations are effective, provides an ideal opportunity for institutions to implement lessons learned to inform the potential arrival of thousands of 
undergraduate students when terms resume. It will also help inform when other higher-risk activities, such as in-person work with human subjects, can safely resume.

\section{LOOKING AHEAD}

Given the length of time that may be required to continue practicing social distancing, it may be years before academic research institutions reach a new normal. Although some beneficial practices may become more routinized (e.g., more alternative work arrangements and virtual meetings), there will undoubtedly be far more deleterious impacts across higher education. Anticipated budget shortfalls from multiple revenue streams suggest that the ongoing pandemic will hamstring institutions financially for years to come. Regarding research specifically, institutions will have fewer internal resources to perform research, invest in research infrastructure, and maintain its workforce. This presents challenges not only for individual institutions but also for the global research enterprise as a whole. In the United States, for example, institutional investments in research comprised $\sim 25 \%$ of total higher education R\&D spending in 2018 (12), a proportion that has increased considerably over the past decade as the percentage of federal investment in research has declined. For countries in which a large percentage of its research workforce consists of international students, such as Australia, travel and visa restrictions could lead to a substantial loss in revenue to support operations and a considerable reduction of the national scientific workforce (13).

The response to COVID-19 has highlighted how the lack of scenario planning and disaster preparedness is a systemic problem spanning virtually all sectors of society. Despite clear guidance and recommendations based on lessons learned from other disasters (14), the research community has much work to do to improve disaster resiliency. The experience of COVID-19 should make it clear that resilience planning should be a priority going forward, but even the best laid plans fail without effective leadership and coordination. Global coordinating bodies like the World Health Organization, or national agencies, must not be sidelined in their ability to advise governments and guide policies.

In the absence of strong national leadership, most institutions had to quickly develop their own plans for ramping down research, supplemented by ad hoc communication between institutions. Coordinating bodies like the Association of American Universities, which represents 63 major research universities in the United States and Canada, are playing much more prominent roles in facilitating ramp-up and other long-range planning. Improved coordination across academia, government, health systems, and industry during crises will also help identify early roles that institutions could play to address critical needs. For example, institutions could deploy expertise, resources, or facilities when there is insufficient incentive or capacity for the private or public sectors to refocus production or facilities rapidly, or when they lack capacity to scale up services such as testing. Considering a broader subset of the R\&D workforce among essential workers, as in Washington state's "Stay Home, Stay Healthy" order, would help facilitate these cross-sector collaborations more effectively while also maintaining other potential lifesaving research unrelated to the pandemic.

Finally, COVID-19 has exacerbated multiple equity issues in the research enterprise that institutions will grapple with in the months and years ahead. This broad-scale disruption of research operations has led to an incalculable number of setbacks for researchers, many of which disproportionately affect early career researchers and their career advancement. These include the cancellation of long-running experiments, the loss of opportunities to collect critical data (e.g., in field and clinical studies), and lack of access to specialized major instrumentation, among many others. Furthermore, longstanding affordability and child and family care disparities across the research workforce-which disproportionally affect women, lower-income support staff, and trainees-are more clear than ever given the sudden and asynchronous sector closures and cost-saving measures implemented at many institutions. Researchers that fall into higher-risk categories on the basis of preexisting health concerns, age, or other immunocompromising conditions face long-term uncertainties around when it is safe to return to work. Systemic solutions such as extensions to promotion and tenure clocks, further deployment of alternative work arrangements, additional fellowship support for trainees, and policies to allow for extended paid and unpaid leave will be essential to stabilize the research workforce.

Moving forward, it will be up to academic institutions, governments, and funding agencies to develop practices and policies that encourage a more resilient, nimble, and equitable research ecosystem during the COVID-19 pandemic and beyond. Deeper investments in the research workforce and infrastructure will surely help; however, governments should also incentivize stronger ties between public health agencies and academic research institutions to ensure that decisionmaking at institutions and across communities is guided by the best available research. If not, it is unlikely that the research enterprise or society as a whole will be any better positioned to help generate solutions, or recover itself, when the next disaster arrives.

\section{REFERENCES AND NOTES}

1. National Center for Science and Engineering Statistics, "National patterns of R\&D resources: 2017-18 data update" (NSF 20-307, National Science Foundation, 2019); https://ncses.nsf.gov/pubs/nsf20307.

2. The Institute for Research on Innovation \& Science, Summary documentation for the IRIS UMETRICS 2019 data release. IRIS (2020) https://doi.org/10.21987/a07t-1c72.

3. H. Tian et al., Science 368, 638 (2020). doi:10.1126/science.abb6105 Medline 
4. Wellcome, Sharing research data and findings relevant to the novel coronavirus (COVID-19) outbreak (2020); https://wellcome.ac.uk/coronavirus-covid19/open-data.

5. The COVID-19 High Performance Computing Consortium; https://covid19-hpcconsortium.org/.

6. AUTM, COVID-19 licensing guidelines; https://autmnet/about-techtransfer/covid19/covid-19-licensing-guidelines.

7. Q. Chen, A. Allot, Z. Lu, Nature 579, 193 (2020). doi:10.1038/d41586-020-006941 Medline

8. E. Dong, H. Du, L. Gardner, Lancet Infect. Dis. 20, 533 (2020). doi:10.1016/S14733099(20)30120-1 Medline

9. C. Rivers et al., "Public health principles for a phased reopening during COVID-19: Guidance for governors" (Johns Hopkins University, 2020); www.centerforhealthsecurity.org/our-work/pubs archive/pubspdfs/2020/reopening-guidance-governors.pdf.

10. American College Health Association (ACHA), "Considerations for reopening institutions of higher education in the COVID-19 era" (ACHA, 2020); www.acha.org/documents/resources/guidelines/ACHA_Considerations_for_Re opening_HHEs_in_the_COVID-19_Era_May2020.pdf.

11. D. M. Altmann, D. C. Douek, R. J. Boyton, Lancet 395, 1527 (2020). doi:10.1016/S0140-6736(20)30985-5 Medline

12. National Center for Science and Engineering Statistics (NCSES), Higher education research and development survey: Fiscal year 2018 (National Science Foundation, 2018); https://ncsesdata.nsf.gov/herd/2018/htm//herd18-dt-tab001.html.

13. F. Larkins et al., "Impact of the pandemic on Australia's research workforce," 6 May 2020, p. 14; www.science.org.au/sites/default/files/rrif-covid19-researchworkforce.pdf.

14. National Academies of Sciences, Engineering, and Medicine, "Strengthening the disaster resilience of the academic biomedical research community: Protecting the nation's investment" (Consensus Study Report, National Academies Press, 2017); https://doi.org/10.17226/24827.

15. U.S. Centers for Disease Control and Prevention (CDC), "Interim guidance for administrators of US institutions of higher education" (CDC, 2020); www.cdc.gov/coronavirus/2019-ncov/community/guidance-iheresponse.html.

\section{ACKNOWLEDGMENTS}

We acknowledge helpful discussions and feedback from several individuals at our institutions, in addition to T. Smith, P. Schiffer, J. Walsh, and anonymous reviewers.

Published online 28 May 2020

10.1126/science.abc5599 


\section{Phased approach and possible mitigations for determining allowable on-site research}

\begin{tabular}{|c|c|c|c|c|}
\hline & $\begin{array}{l}\text { COMMUNITY } \\
\text { TRANSMISSION } \\
\text { STATUS (15) }\end{array}$ & ON-SITE ACTIVITIES PERMITTED & MITIGATIONS & RESEARCH WORKFORCE IMPLICATIONS \\
\hline $\begin{array}{l}\text { Phase } 0 \\
\text { (current state) }\end{array}$ & Substantial & $\begin{array}{l}\text { Only essential work to ensure laboratory, } \\
\text { animal, or patient safety; maintenance } \\
\text { of equipment, materials, or long-running } \\
\text { experiments; COVID-related research }\end{array}$ & $\begin{array}{l}\text { Strict building access; personal protective } \\
\text { equipment required; all work done remotely, } \\
\text { if possible }\end{array}$ & $\begin{array}{l}\text { Only essential staff with considerable } \\
\text { training allowed; travel disrupted; } \\
\text { substantial absenteeism owing } \\
\text { to illness, childcare, or family care; } \\
\text { high-risk workers restricted }\end{array}$ \\
\hline $\begin{array}{l}\text { Phase } 1 \\
\text { (ramp-up) }\end{array}$ & Moderate & $\begin{array}{l}\text { Gradual addition of laboratory and studio } \\
\text { work and regional field research not } \\
\text { involving human subjects; widely used } \\
\text { shared facilities reopen }\end{array}$ & $\begin{array}{l}\text { Control building and/or room access; require } \\
\text { temperature and symptom checking, physical } \\
\text { distancing, strict limits on occupancy in labs, use } \\
\text { of masks, enhanced cleaning procedures, and } \\
\text { closures of exposed workspaces and buildings; } \\
\text { testing and contact tracing if and when available }\end{array}$ & $\begin{array}{l}\text { Fraction of researchers allowed } \\
\text { depending on need, training, and } \\
\text { willingness to return }\end{array}$ \\
\hline Later phases & $\begin{array}{l}\text { Minimal to } \\
\text { none }\end{array}$ & $\begin{array}{l}\text { Continued gradual addition of more on-site } \\
\text { research activities, use of office and shared } \\
\text { spaces, and relaxation of travel prohibitions; } \\
\text { research with human subjects will require } \\
\text { the highest level of scrutiny }\end{array}$ & $\begin{array}{l}\text { Gradual loosening of some control measures, } \\
\text { depending on performance metrics }\end{array}$ & $\begin{array}{l}\text { Phased introduction of researchers } \\
\text { working in-person with human } \\
\text { subjects; additional trainees; high-risk } \\
\text { workers only when conditions allow }\end{array}$ \\
\hline
\end{tabular}

\section{Should we ramp up?}

Checklist for assessing when more research activity is permissible on-site

- Does local or regional public health guidance permit a gradual increase in research activity?

- Does the institution have reliable access to supplies such as personal protective equipment, disinfectants, etc.?

- Does the institution have the ability to track symptoms, conduct testing, and/or trace and inform contacts?

- Have ramp-up procedures and plans been communicated to researchers?

- Are departments and individual labs ready to work safely?

- Are the support units (facilities, environmental health, security, custodial, transportation) prepared to support more on-site activity? 